\title{
The pattern of methacholine responsiveness in mice is dependent on antigen challenge dose
}

\author{
Graeme R Zosky*1,2, Christophe von Garnier 1,2, Philip A Stumbles 1,2, \\ Patrick G Holt ${ }^{1,2}$, Peter D Sly ${ }^{1,2}$ and Debra J Turner ${ }^{1,2}$
}

Address: ${ }^{1}$ Telethon Institute for Child Health Research, West Perth, 6872, Australia and ${ }^{2}$ Centre for Child Health Research, University of Western Australia, Crawley, 6009, Australia

Email: Graeme R Zosky* - graemez@ichr.uwa.edu.au; Christophe von Garnier - christophe@ichr.uwa.edu.au; Philip A Stumbles - phils@ichr.uwa.edu.au; Patrick G Holt - patrick@ichr.uwa.edu.au; Peter D Sly - peters@ichr.uwa.edu.au; Debra J Turner - debrat@ichr.uwa.edu.au

* Corresponding author

Published: 23 September 2004

Respiratory Research 2004, 5:15 doi:10.1 I86/1465-992I-5-15
Received: 02 July 2004

Accepted: 23 September 2004

This article is available from: http://respiratory-research.com/content/5/I/I5

(c) 2004 Zosky et al; licensee BioMed Central Ltd.

This is an open-access article distributed under the terms of the Creative Commons Attribution License (http://creativecommons.org/licenses/by/2.0), which permits unrestricted use, distribution, and reproduction in any medium, provided the original work is properly cited.

\begin{abstract}
Background: Considerable variation exists in the protocols used to induce hyperresponsiveness in murine models of allergic sensitisation. We examined the effect of varying the number of antigen exposures at challenge on the development of methacholine responsiveness in systemically sensitised mice.
\end{abstract}

Methods: BALB/c mice were sensitised with ovalbumin (OVA), challenged with I, 3 or 6 OVA aerosols. Lung function was measured using low frequency forced oscillations and partitioned into components representing the airways $\left(R_{a w}\right)$ and lung parenchyma (tissue damping $(G)$ and tissue elastance $(H)$ ). Responsiveness to inhaled methacholine $(M C h)$, inflammatory cell profile and circulating IgE were assessed 24 and 48 hours after challenge. The threshold dose of MCh required to elicit a detectable response (sensitivity) and response to $30 \mathrm{mg} \cdot \mathrm{mL}^{-1}$ (maximal response) were determined for each compartment.

Results: Sensitivity; All three OVA protocols resulted in an increased sensitivity to $M C h$ in $R_{a w}$ but not in $\mathrm{G}$ or $\mathrm{H}$. These responses where present at 24 and $48 \mathrm{hrs}$, except I OVA aerosol in which changes had resolved by $48 \mathrm{hrs}$. Maximal response; I OVA aerosol increased maximal responses in $\mathrm{R}_{\mathrm{aw}}$, $\mathrm{G}$ and $\mathrm{H}$ at $24 \mathrm{hrs}$, which was gone by $48 \mathrm{hrs}$. Three OVA aerosols increased responses in $\mathrm{H}$ at $48 \mathrm{hrs}$ only. Six OVA challenges caused increases in $R_{a w}, G$ and $H$ at both 24 and 48 hrs. Eosinophils increased with increasing antigen challenges. IgE was elevated by OVA sensitisation but not boosted by OVA aerosol challenge.

Conclusions: The pattern of eosinophilia, lgE and MCh responsiveness in mice was determined by antigen dose at challenge. In this study, increased sensitivity to MCh was confined to the airways whereas increases in maximal responses occurred in both the airway and parenchymal compartments. The presence of eosinophilia and IgE did not always coincide with increased responsiveness to inhaled $\mathrm{MCh}$. These findings require further systematic study to determine whether different mechanisms underlie airway and parenchymal hyperresponsiveness post antigen challenge. 


\section{Background}

Persistent asthma is an allergic disease characterised by airway inflammation ([1-5]) and hyperresponsiveness to external stimuli ([1]). Mouse models of allergic airway sensitisation are often used to elucidate the pathobiology of this disease ([6-8]).

To date, a number of techniques have been used to measure changes in lung function in response to bronchoconstricting agents in murine models of allergic bronchopulmonary inflammation (see $[6,8,9]$ for reviews). One method that has gained recent popularity is unrestrained barometric plethysmography, which uses a 'pseudo-flow' measurement to derive a dimensionless parameter known as enhanced pause (Penh). There are now several publications in the literature which claim to have documented airway hyperresponsiveness in allergen-driven murine models based on methacholine induced changes in Penh. However, it has also been well documented that Penh does not correlate with changes in the physiology of the lung ([10-14]), especially in chronic disease states ([15]). In contrast, the low frequency forced oscillation technique (LFOT) is able to provide sensitive measurements of respiratory system input impedance (Zrs) in the mouse, that are partitioned into components representing airway and parenchymal compartments by fitting the constant-phase model ([16-18]). Using LFOT, Tomioka et al. ([17]) found that systemic sensitisation followed by three antigen challenges, one of the most common allergen models utilised in studies using Penh, resulted in hyperresponsiveness that was confined primarily to the tissue compartment of the lung. This has important implications for the interpretation of results obtained with Penh that have demonstrated mechanisms underlying allergic inflammation in mice given that a significant portion of the respiratory system hyperreactivity to $\mathrm{MCh}$ in human asthmatics is a result of the response of the conducting airways ([19]).

One of the most common methods for inducing allergic bronchopulmonary inflammation in mice involves systemic sensitisation with a specific antigen and Th-2 skewing adjuvant, usually ovalbumin (OVA) adsorbed onto aluminium hydroxide (Alum), followed by airway challenge with the same antigen ([20-22]). However, considerable variations exist between studies in terms of the dose of antigen used during airway challenge. To date, a number of studies have found that airway hyperresponsiveness is increased by increasing the dose of antigen at challenge ([23-25]). However, these studies, which used different doses of antigen at challenge as part of a broader intervention protocol, have used Penh $([23,24])$ or a measure of total lung resistance ([25]) to examine the resulting changes in lung physiology. As yet, no studies have systematically examined the effect of the dose of antigen at challenge on the subsequent development of hyperresponsiveness using a technique that is able to partition the reactivity of the lungs into airways and tissue compartments.

Hyperresponsiveness of the respiratory system to bronchoconstricting agents, and other outcome parameters such as those that reflect inflammation and allergic sensitisation, are often measured at different times post challenge. In an examination of the kinetics of hyperresponsiveness in an OVA model of allergic sensitisation in mice using a single dose of antigen at challenge, Tomkinson et al. ([26]) found that responsiveness to methacholine $(\mathrm{MCh})$ is maximal 24 hours post challenge, has begun to resolve by 48 hours, and has returned to baseline levels beyond that time. The kinetics of responsiveness to MCh in other studies, however, are often overlooked and it is yet be determined if altering the dose of antigen at challenge has an influence on the timing of peak responsiveness to bronchoconstricting agents.

The aim of this study was to systemically investigate the effect of antigen dose at challenge on the pattern of hyperresponsiveness to inhaled $\mathrm{MCh}$ in a murine model of allergic bronchopulmonary inflammation.

\section{Methods \\ Animals}

8 week old specific pathogen free female BALB/c mice were purchased from the Animal Resources Centre, Murdoch, Western Australia. Mice were housed in a controlled environment with a $12 \mathrm{hr}$ light:dark cycle and provided with an OVA free diet and acidified water ad libitum. All experiments were approved by the Institutional Animal Ethics and Experimentation Committee.

\section{Sensitisation protocols}

Mice were sensitised by intraperitoneal (i.p.) injection with $20 \mu \mathrm{g}$ of OVA (Sigma, St Louis, USA) suspended in $200 \mu \mathrm{L}$ of Alum (Alu-gel-S, Serva, Heidelberg, Germany) on days 0 and 14 . Mice were then challenged with either 1,3 or 6 OVA ( $1 \% \mathrm{w} / \mathrm{v}$ in PBS) aerosols delivered with an ultrasonic nebuliser (UltraNeb ${ }^{\circledR}$, DeVilbiss, Somerset, Pennsylvania) for 30 minutes on consecutive days starting at day 21 (Fig 1). Two additional groups of mice served as controls; a naïve group and a group sensitised with i.p. OVA and challenged with a single PBS aerosol using the protocol described above.

\section{Respiratory mechanics}

Changes in Zrs were measured using a modification of the low frequency forced-oscillation technique (LFOT) as described previously ([27]). Briefly, mice were anaesthetised with an i.p. injection of a solution containing xylazine ( $2 \mathrm{mg} \cdot \mathrm{mL}^{-1}$, Troy Laboratories, NSW, Australia) and 

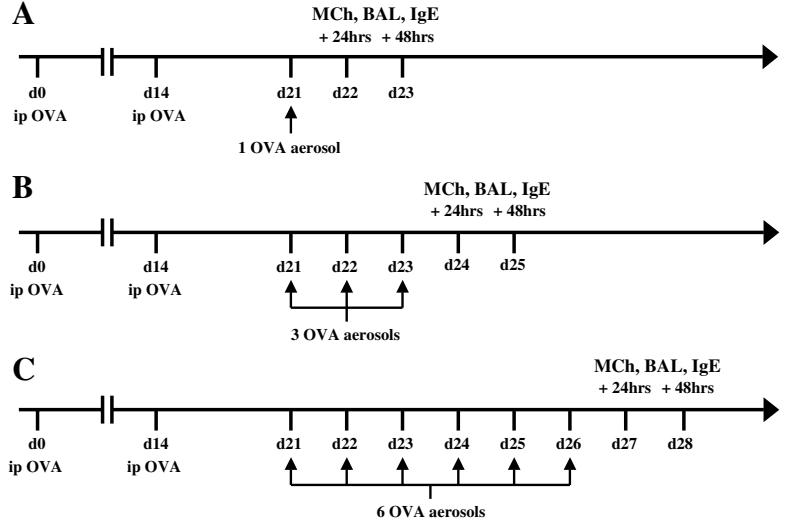

\section{Figure I}

Timeline for sensitisation and data collection. Timeline for the protocols used to induce allergic bronchopulmonary inflammation and timing for bronchoalveolar lavage (BAL), serum IgE measurement and assessment of hyperresponsiveness to inhaled methacholine $(\mathrm{MCh})$. Mice were systemically sensitised with two intraperitoneal injections of OVA/Alum on day 0 and I4, challenged with either I (A), 3 (B) or 6 (C) OVA aerosols (1\%) for 30 minutes starting at day 21 .

ketamine (40 mg.mL-1 ${ }^{-1}$ Troy Laboratories, NSW, Australia) at a dose of $0.01 \mathrm{~mL} \cdot \mathrm{g}^{-1}$. Mice were tracheostomised with a $10 \mathrm{~mm}$ section of polyethylene tubing $(1.27 \mathrm{~mm}$ OD: $0.86 \mathrm{~mm}$ ID) and ventilated (flexiVent, Scireq, Montreal, Canada) at 450 b. min $^{-1}$ with a tidal volume of 8 mL. $\mathrm{kg}^{-1}$ and a positive end expiratory pressure (PEEP) of 2 $\mathrm{cmH}_{2} \mathrm{O}$. The lung volume history of the mice was standardised prior to measurement of lung mechanics using two deep inflations and three P-V curves. The respiratory system input impedance (Zrs) was measured during periods of apnea using a 16 s signal containing 19 mutually prime sinusoidal frequencies ranging from 0.25 to 19.625 $\mathrm{Hz}$. The constant phase model ([16]) was then fit to the real and imaginary parts of the Zrs spectrum allowing the calculation of airway resistance $\left(R_{a w}\right)$, tissue damping $(G)$, tissue elastance $(H)$ and hysteresivity $(\eta)([28])$.

\section{Methacholine responsiveness}

Changes in respiratory mechanics following inhaled $\mathrm{MCh}$ were measured either 24 or 48 hrs after the last OVA aerosol. Following measurement of baseline Zrs, mice were exposed to a $90 \mathrm{~s}$ saline aerosol delivered with an ultrasonic nebuliser (UltraNeb ${ }^{\circledR}$, Devilbiss, Somerset, Pennsyl- vania). Zrs was then measured every minute for the next 5 minutes. This aerosol procedure was repeated with $1 / 2$ $\log _{10}$ incremental doses of MCh from 0.1 to $30 \mathrm{mg} \cdot \mathrm{mL}^{-1}$ with Zrs measured every minute for at least 5 minutes after the aerosol until the parameters calculated from the constant phase model had peaked.

\section{Inflammatory cell counts}

Separate groups of mice, sensitised using the same protocol described above, were anaesthetised and tracheostomised 24 or 48 hrs after their last aerosol. BAL fluid was collected by slowly infusing and withdrawing a $1 \mathrm{~mL}$ aliquot of PBS containing BSA (bovine serum albumin, 20 mg.mL-1, CSL, Victoria, Australia) and lidocaine (35 mg.mL ${ }^{-1}$, Sigma, St Louis, USA) from the lungs three times. The BAL was then centrifuged at $2000 \mathrm{rpm}$ for 4 mins. The supernatant was removed and the pellet resuspended in PBS. The cells were stained with trypan blue to determine viability and the total cell count (TCC) obtained by counting the cells with a haemocytometer. Differential counts were obtained from the cytospin sample, stained with Leishman's stain and examined using light microscopy. Three hundred cells were counted from each sample to determine the relative proportions of each cell type.

\section{Serum IgE}

In a separate group of mice, serum samples were periodically collected for analysis of total IgE. An additional control group was included in the analysis of serum $\operatorname{IgE}$ consisting of mice sensitised with PBS/Alum. Sera were diluted 1:7.5 in Delfia Assay buffer (Wallac Oy, Turku, Finland). The diluted sera were analysed for the presence of total IgE by time-resolved fluorescence (TRF) assays. Briefly, 96-well plates (Nunc Maxisorp, Denmark) were coated overnight at $4^{\circ} \mathrm{C}$ with anti-mouse IgE (R35-72; BD PharMingen, San Diego, USA). Plates were blocked with $200 \mu \mathrm{l}$ of $0.5 \%$ BSA in TRIS-HCl pH 7.4 for 1 hour at room temperature on a plate shaker. For all subsequent steps a volume of $50 \mu \mathrm{l}$ per well was used and incubations were performed for 1 hour at room temperature unless otherwise indicated. Between steps, plates were washed five times with wash buffer (TRIS-HCl pH 7.8 Tween20). Mouse anti-TNP IgE (BD PharMingen, San Diego, USA) was used as an interassay standard. Biotinylated antimouse IgE (R35-118; BD PharMingen, San Diego, USA) was added to the wells at $2 \mu \mathrm{g} \cdot \mathrm{mL}^{-1}$. Straptavidin-conjugated Europium (Wallac Oy, Turku, Finland) was incubated at 1:500 for 30 minutes and plates washed eight times thereafter. Delfia enhancement solution (Wallac Oy, Turku, Finland) was added and the plates were agitated on a shaker for 10 minutes prior to reading the fluorescence on a Wallac Victor 2 counter (Wallac Oy, Turku, Finland). The detection limit of this assay is approximately 100 ng. $\mathrm{mL}^{-1}$. 


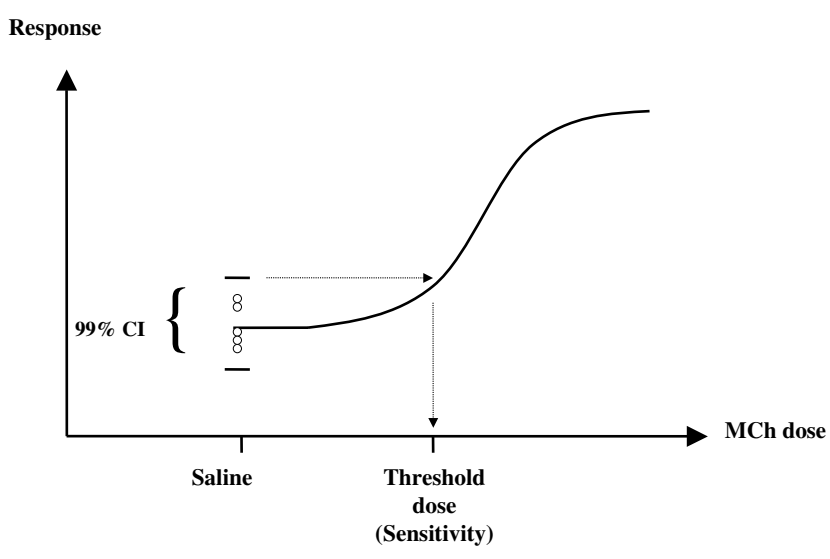

Figure 2

Technique for sensitivity calculation. Schematic representation of the technique used for calculation of the threshold dose of MCh (sensitivity) required to induce a detectable increase in $R_{a w}, G$ and $H$.

\section{Statistical analysis}

$\log _{10}$ transformed inflammatory cell and immunoglobulin data were compared using ANOVA and Tukey's posthoc test. Responses in $R_{a w}$ and $G$ to inhaled MCh at the maximum dose used $\left(30 \mathrm{mg} \cdot \mathrm{mL}^{-1}\right)$ were expressed as a percentage of the response to the saline aerosol and compared using non-parametric ANOVA on ranks and Dunn's post-hoc test. Responses in H were expressed as a percentage of the response to saline, $\log _{10}$ transformed and compared using ANOVA and Tukey's post-hoc test. The threshold dose of MCh where there was a detectable change in $\mathrm{R}_{\mathrm{aw}}$ $\mathrm{G}$ or $\mathrm{H}$ (termed sensitivity hereafter) was interpolated from the raw dose response curve as the upper limit of the $99 \% \mathrm{CI}$ of the 5 measurements taken following the saline aerosol (Fig. 2). The sensitivity data were compared using ANOVA and Tukey's post-hoc test. All data were analysed using SigmaStat 2.03 and p values $<0.05$ were deemed to be significant.

\section{Results}

\section{Methacholine responsiveness}

The degree and time of observed maximum MCh induced responses in $R_{a w}, G$ and $H$ varied substantially between treatments (Fig. 3). A summary of statistical comparisons of sensitivity to MCh and percentage response to the maximum dose (30 mg. $\left.\mathrm{mL}^{-1}\right)$ between treatment groups and naïve mice is presented in Table 1 . Sensitisation followed by challenge with a single PBS aerosol did not cause an increase in sensitivity or maximum responsiveness to MCh compared to naïve mice.

\section{One OVA aerosol}

A single OVA aerosol was sufficient to induce a significant increase in $\mathrm{MCh}$ responsiveness in the airways, seen as both a lower threshold dose of MCh required to induce a response (increased sensitivity) and increased response at the 24 hour time point (Table 1). In the parenchymal compartment, no increase in sensitivity was seen but a significant increase in maximal response was seen for both $G$ and $\mathrm{H}$. This heightened sensitivity and response had diminished, back to the level seen in naive mice, 48 hours after the OVA aerosol.

\section{Three OVA aerosols}

Three OVA aerosols resulted in significantly increased airway (but not parenchymal) sensitivity to $\mathrm{MCh}$ at both the 24 and 48 hour time points (Table 1 ). However, there was no increase in maximum response at 24 hours in $\mathrm{R}_{\mathrm{aw}^{\prime}} \mathrm{G}$ or $\mathrm{H}$ and only an increased response in $\mathrm{H}$ after 48 hours but not $R_{a w}$ and $G$.

\section{Six OVA aerosols}

Six OVA aerosols resulted in both significantly increased airway sensitivity and maximal responses to MCh at 24 and 48 hours post-challenge. Increased maximal responses, but not increased sensitivity, were also seen in the parenchymal compartment at both the 24 and 48 hour time points.

\section{Inflammatory cell counts}

Challenge with a single PBS aerosol following systemic sensitisation with OVA did not cause a significant increase in TCC in the BAL $(\mathrm{p}=0.552)$ compared to naïve mice (Fig. 4). There was, however, a significant increase in TCC in mice challenged with a single OVA aerosol $(\mathrm{p}=0.032)$ and a further increase in TCC following 3 OVA challenges $(\mathrm{p}<0.001)$. Exposure to 6 OVA aerosols did not cause any further increase in TCC above levels observed in mice exposed to 3 OVA aerosols $(p=0.805)$ but remained significantly higher than mice challenged with 1 OVA aerosol $(p<0.001)$. Time of sampling after the last aerosol with any of the protocols did not have a significant impact on TCC ( $\mathrm{p}=0.357)$.

The number of aeroallergen challenges also had a significant impact on the number of eosinophils $(\mathrm{p}<0.001)$ and macrophages $(p<0.001)$ in the BAL. There were significant increases in the number of eosinophils in sensitised mice challenged with $1(\mathrm{p}=0.032), 3(\mathrm{p}<0.001)$ and 6 $(\mathrm{p}<0.001)$ OVA aerosols (Fig. 5) compared to naïve mice. The numbers of eosinophils in the BAL of mice exposed to 3 and 6 aerosols were significantly higher than those exposed to a single OVA aerosol ( $p<0.001$ and $p<0.001$ respectively) but were not significantly different from each other $(p=0.805)$. The number of macrophages in the BAL were also higher in mice exposed to $3(\mathrm{p}<0.001)$ 
1 OVA aerosol

Airway resistance $\left(R_{\text {aw }}\right)$

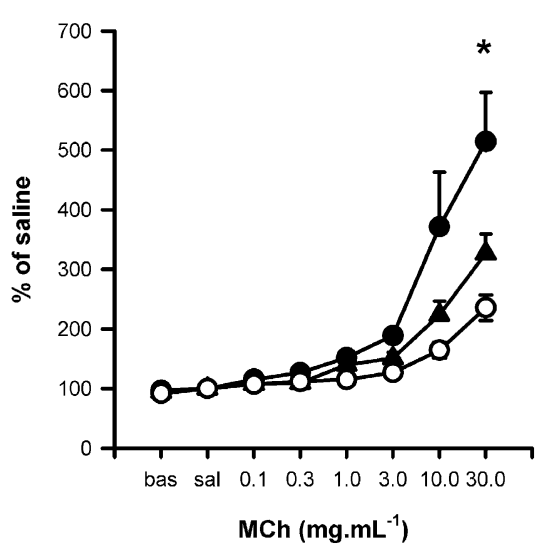

Tissue damping (G)

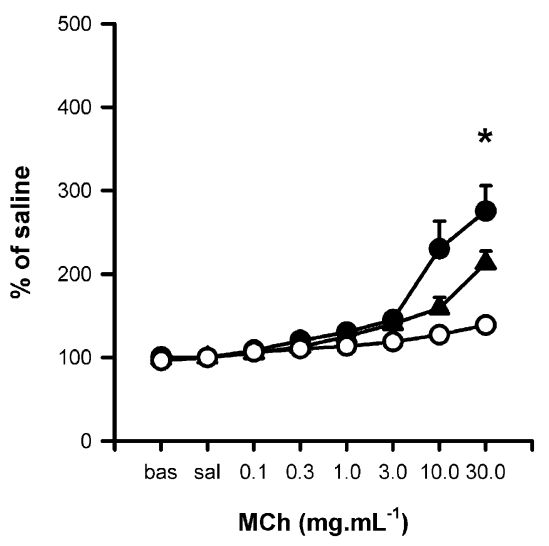

Tissue elastance $(H)$

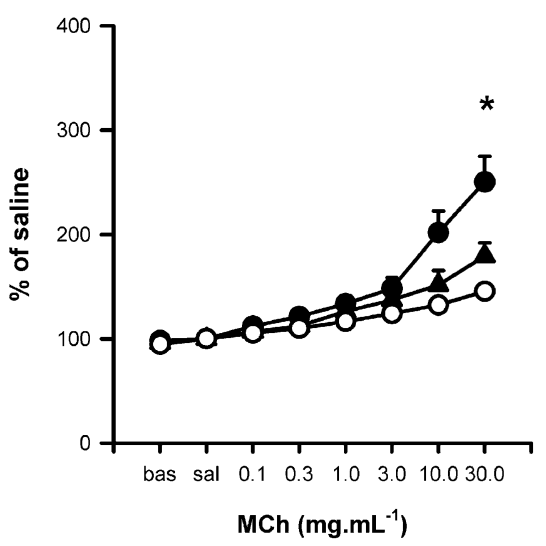

3 OVA aerosols

Airway resistance $\left(R_{\text {aw }}\right)$

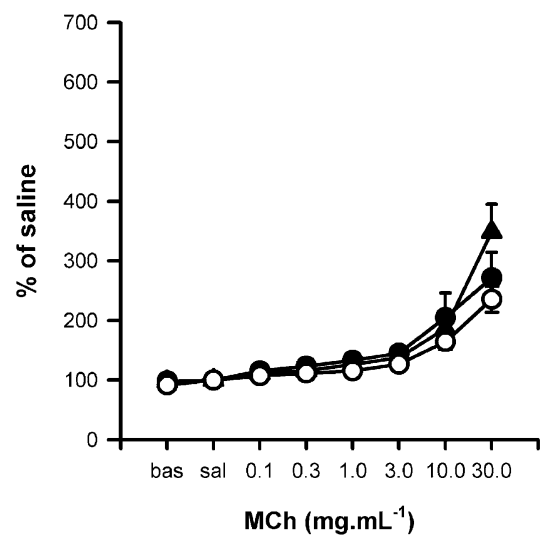

Tissue damping (G)

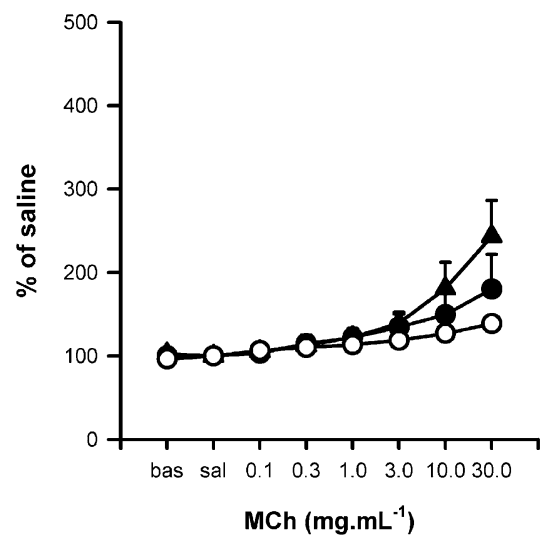

Tissue elastance $(\mathrm{H})$

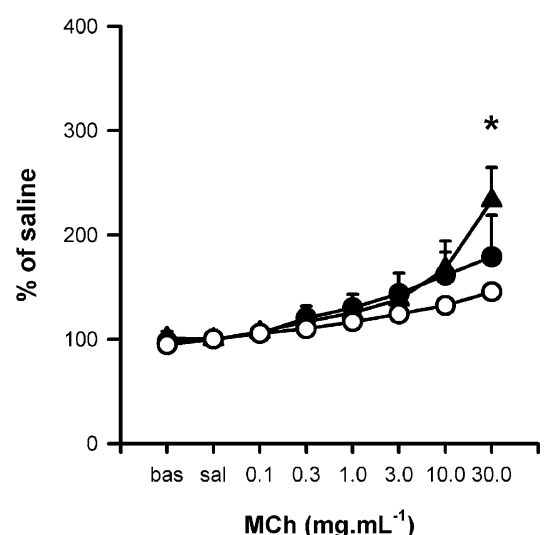

6 OVA aerosols

Airway resistance $\left(R_{\text {aw }}\right)$

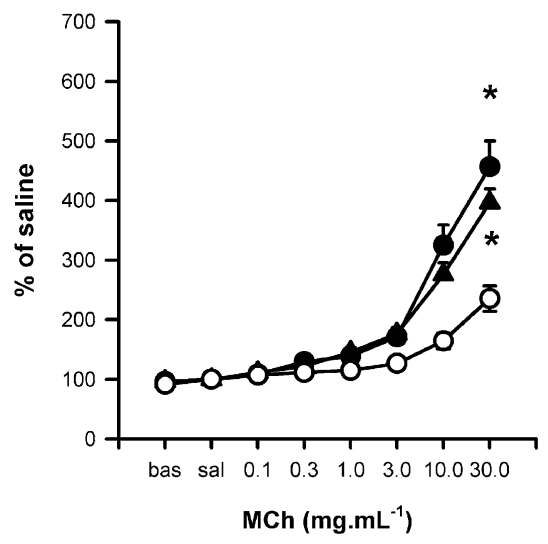

Tissue damping (G)

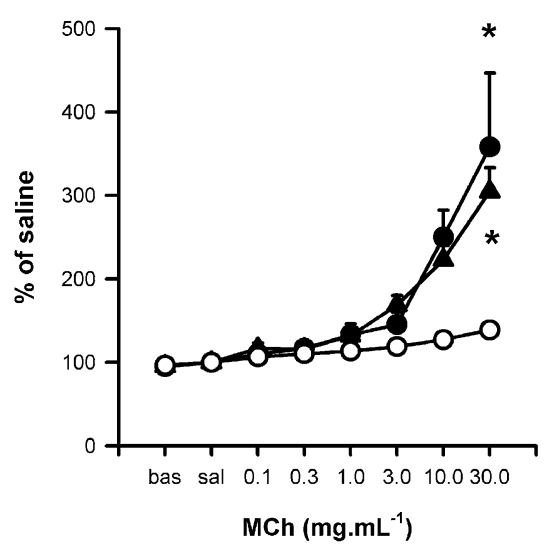

Tissue elastance $(\mathrm{H})$

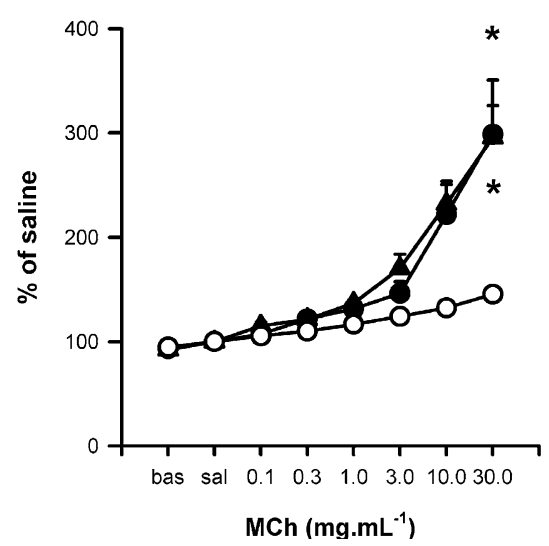

Figure 3

Dose response curves to inhaled methacholine. Dose response curves (expressed as a \% of the response to saline aerosol) for mice systemically sensitised with OVA/Alum and challenged via the airways with I (left), 3 (centre) or 6 (right) OVA aerosols. Mice were challenged $24(\bullet)$ or $48(\Delta)$ hours after the last OVA aerosol. Dose response curves from naïve mice $(O)$ are also shown. All data are expressed as mean \pm SEM $(n=7-8)$. * indicates significance $(p<0.05$ vs naïve mice; ANOVA on Ranks, Dunn's post-hoc for $\mathrm{R}_{\mathrm{aw}}$ and $\mathrm{G}$; ANOVA, Tukey's post-hoc for $\mathrm{H}$ ). 
Table I: Summary of sensitivity and maximum responses to methacholine in airway and parenchymal lung compartments. Summary of the threshold dose (sensitivity) required to elicit a detectable increase in airway resistance $\left(R_{\text {aw }}\right)$, tissue damping $(G)$ and tissue elastance $(H)$ for naïve mice, mice systemically sensitised with OVA/Alum and challenged with PBS and mice systemically sensitised and challenged with OVA. Also shown is the percentage change in $R_{a w}, G$ and $H$ in response to the maximum does of methacholine used (30 $\mathrm{mg} \cdot \mathrm{mL}^{-1}$ ). Data are presented as the mean (SEM).

\begin{tabular}{|c|c|c|c|c|c|c|c|c|c|c|c|c|c|}
\hline \multirow[t]{2}{*}{ Challenge } & \multirow{2}{*}{$\begin{array}{c}\text { Assessed after last } \\
\text { aerosol (hr) }\end{array}$} & \multicolumn{6}{|c|}{ Sensitivity - Threshold dose of MCh ( $\left.\mathrm{mg} \cdot \mathrm{mL}^{-1}\right)$} & \multicolumn{6}{|c|}{ Response at $30 \mathrm{mg} \cdot \mathrm{mL}^{-1} \mathrm{MCh}$} \\
\hline & & \multicolumn{2}{|c|}{ Raw } & \multicolumn{2}{|l|}{ G } & \multicolumn{2}{|l|}{$\mathbf{H}$} & \multicolumn{2}{|c|}{ Raw $\S$} & \multicolumn{2}{|c|}{ G§ } & \multicolumn{2}{|l|}{$\mathbf{H}^{\S}$} \\
\hline & & & $\mathrm{P}^{*}$ & & $\mathrm{P}^{*}$ & & $\mathrm{P}^{*}$ & & $\mathrm{P}^{*}$ & & $\mathrm{P}^{*}$ & & $\mathrm{P}^{*}$ \\
\hline Naïve & - & $0.54(0.14)$ & - & $0.5 \mathrm{I}(0.25)$ & - & $0.10(0.02)$ & - & $235.5(21.5)$ & - & $138.8(6.1)$ & - & $145.4(5.1)$ & - \\
\hline I PBS aerosol & 24 and 48 pooled & $0.55(0.30)$ & ns & $0.25(0.10)$ & ns & $0.06(0.01)$ & ns & $242.9(19.1)$ & ns & $|4| .5(4.7)$ & ns & $143.4(2.7)$ & ns \\
\hline \multirow[t]{2}{*}{ I OVA aerosol } & 24 & $0.09(0.03)$ & 0.012 & $0.15(0.04)$ & ns & $0.05(0.01)$ & ns & $514.0(82.7)$ & $<0.05$ & $275.5(30.6)$ & $<0.001$ & $250.2(24.5)$ & $<0.001$ \\
\hline & 48 & $0.46(0.19)$ & ns & $0.18(0.05)$ & ns & $0.17(0.07)$ & ns & $326.4(32.6)$ & ns & $213.0(14.6)$ & ns & $179.3(12.6)$ & ns \\
\hline \multirow[t]{2}{*}{3 OVA aerosols } & 24 & $0.12(0.03)$ & 0.012 & $0.35(0.20)$ & ns & $0.06(0.01)$ & ns & $271.2(43.1)$ & ns & $\mid 80.3(4 \mid .7)$ & ns & 178.9(39.9) & ns \\
\hline & 48 & $0.20(0.07)$ & 0.034 & $0.16(0.04)$ & ns & $0.08(0.01)$ & ns & $348.8(46.0)$ & ns & $243.6(42.7)$ & ns & $233.0(31.6)$ & 0.045 \\
\hline \multirow[t]{2}{*}{6 OVA aerosols } & 24 & $0.17(0.05)$ & 0.019 & $0.12(0.05)$ & ns & $0.06(0.01)$ & ns & $456.7(43.4)$ & $<0.05$ & $358.2(88.4)$ & $<0.05$ & $298.5(52.2)$ & 0.02 \\
\hline & 48 & $0.16(0.05)$ & 0.034 & $0.15(0.06)$ & ns & $0.06(0.01)$ & ns & $396.0(23.3)$ & $<0.05$ & $304.8(28.5)$ & $<0.05$ & $295.6(30.6)$ & 0.018 \\
\hline
\end{tabular}

$\S$ expressed as a $\%$ of saline response

$*$ vs naïve values

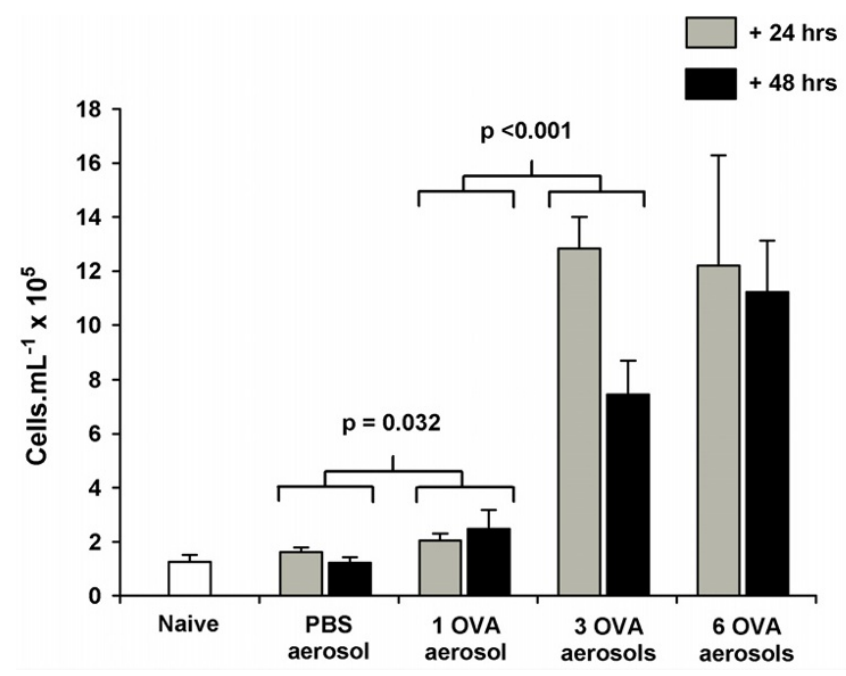

Figure 4

Total cell counts from bronchoalveolar lavage. Total cell counts (TCC) from the bronchoalveolar lavage $(B A L)$ of naïve $B A L B / c$ mice, mice systemically sensitised and challenge with OVA aerosols and mice systemically sensitised with OVA and challenged with PBS. Samples were collected 24 (grey) and 48 (black) hours after the last aerosol. Data are expressed as mean \pm SEM $(n=5-6)$. Exposure to a PBS aerosol following antigen sensitisation did not cause an increase in TCC $(p=0.552)$. In contrast, a single OVA aerosol was sufficient to cause a significant increase in TCC $(p=0.032)$. Exposure to 3 OVA aerosols caused a further increase in TCC $(p<0.001)$ but 6 OVA aerosols did not cause an increase in TCC beyond those observed in mice exposed to 3 OVA aerosols ( $p=0.805)$. and 6 ( $\mathrm{p}<0.001)$ OVA aerosols compared to naïve mice. As with TCC, time of sampling after the last aerosol did not have a significant impact on the number of eosinophils $(\mathrm{p}=0.357)$ or macrophages $(\mathrm{p}=0.079)$ in the BAL. Low levels of neutrophils were observed in BALs from OVA challenged mice sampled at 24 hours but not in mice sampled 48 hours after the last OVA aerosol (Fig. 5). Lymphocyte numbers were not significantly elevated in the BALs from any of the treatment groups (data not shown).

\section{Serum IgE}

Total serum IgE was significantly increased at day 21 ( $\mathrm{p}<$ 0.001), 7 days after the second injection of OVA/Alum, compared to naïve mice (Fig. 6). In contrast, serum IgE levels at day 14, after a single injection, were not significantly elevated ( $\mathrm{p}=0.438$ ) compared to naïve mice. The total serum IgE response to systemic sensitisation, in the absence of subsequent antigen aerosol challenge, peaked at day 22 and partially declined by day 27 . However, this decrease was not statistically significant $(\mathrm{p}=0.511)$. There was no further increase in the total serum IgE in mice that were sensitised and subsequently challenged with OVA aerosols compared to those that were only systemically sensitised $(p=0.842)$. Total serum IgE levels were not significantly greater in mice sensitised with PBS/Alum and challenged with OVA (data not shown).

\section{Discussion}

Varying the number of aeroallergen challenges in a systemically sensitised murine model of allergic bronchopulmonary inflammation altered the degree and timing of hyperresponsiveness to inhaled MCh. A single OVA 


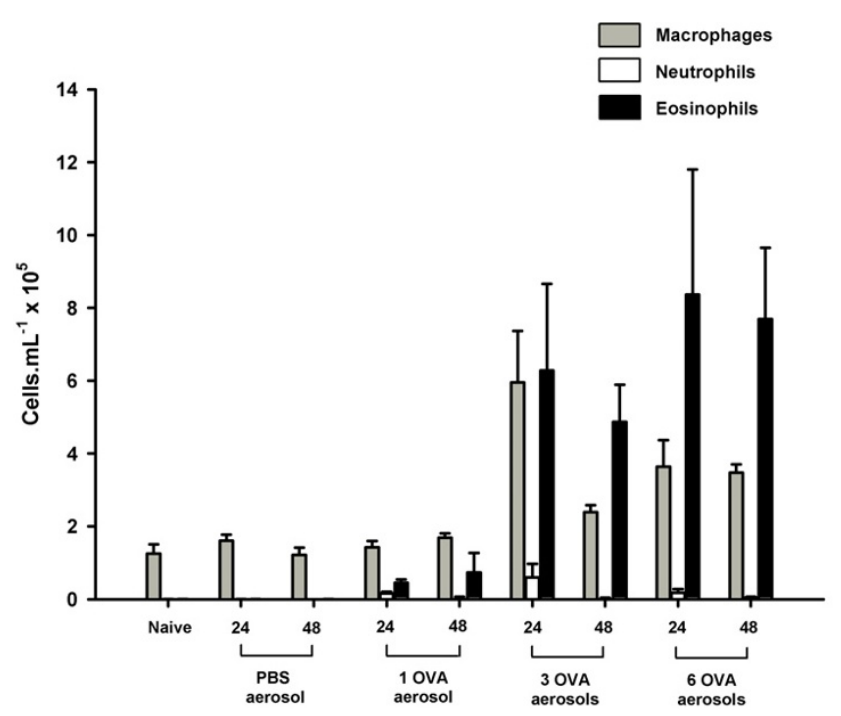

Figure 5

Differential cell counts from bronchoalveolar lavage. Differential cell counts from the bronchoalveolar lavage (BAL) of naïve $B A L B / c$ mice, mice systemically sensitised and challenge with I,3 or 6 OVA aerosols and mice systemically sensitized with OVA and challenged with a single PBS aerosol. BALs were collected 24 and 48 hours after the last aerosol. Data are expressed as mean \pm SEM $(n=5-6)$. There was a significant increase in the number of eosinophils $(p=0.032)$ in the BAL following a single OVA aerosol. Exposure to 3 or more OVA aerosols caused a further increase in the number eosinophils ( $p<0.00 \mathrm{I})$, compared to I OVA aerosol, and an increase in the number of macrophages $(p<0.00 \mathrm{I})$ compared to naïve mice. There were neutrophils present in the BALs of some mice but only in those groups sensitised and challenged with OVA and only in BALs sampled 24 hours after the last aerosol.

challenge increased airway sensitivity to inhaled MCh 24 hours after the challenge, while sensitivity remained elevated for 48 hours after three and six challenges. OVA challenge did not increase parenchymal sensitivity at any level. In contrast to sensitivity measurements, the maximum response to $30 \mathrm{mg} \cdot \mathrm{mL}^{-1} \mathrm{MCh}$ showed a variable pattern. A transient response was observed in both airway and parenchymal compartments after a single OVA aerosol. After 3 OVA aerosols significant increases were seen in the tissue compartment at 48 hours, while after 6 OVA aerosols an elevated response was seen in the airway and parenchymal compartments that persisted beyond 48 hours. There was a significant influx of inflammatory cells in the BAL in response to OVA aerosols, however, the presence of this inflammation did not always result in hyperessponsiveness to inhaled MCh.

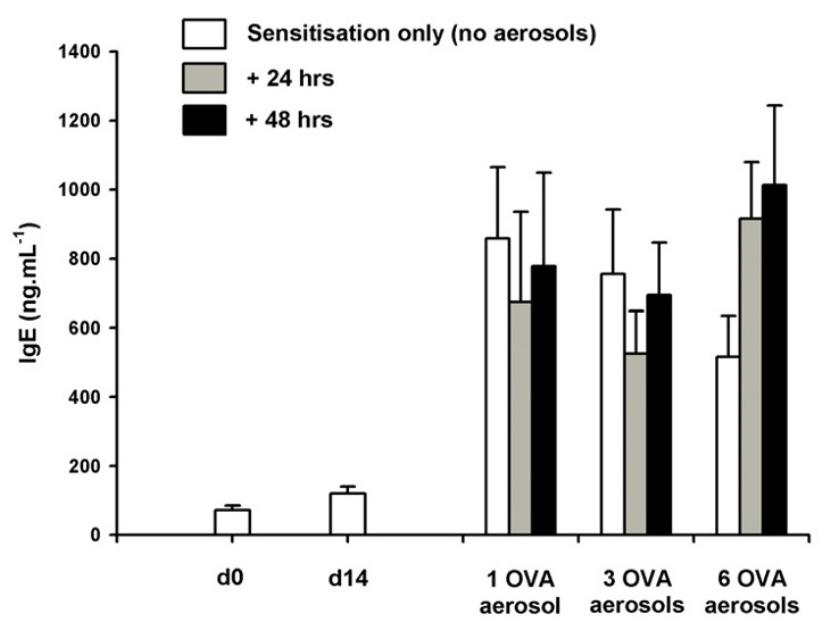

Figure 6

Total serum IgE obtained from time resolved fluorescence. Total IgE obtained from time resolved fluorescence assay of serum collected from systemically sensitised (i.p. OVA/Alum on day 0 and day 14) but not challenged with aerosolised antigen (white bars). The vertical bars represent total serum IgE from mice sensitised and challenged with either I, 3 or 6 OVA aerosols. Serum samples from these mice were collected 24 (grey bars) and 48 (black bars) hours after the last aerosol. Data are expressed as mean \pm SEM ( $n$ $=10$ ). Two intraperitoneal injections of OVA/Alum were sufficient to induce increased levels total IgE by day 21 ( $p<$ $0.00 \mathrm{I}$ ) compared to naïve mice. Exposure to OVA aerosol challenges did not cause a further increase in total $\lg E(p=$ 0.842).

Murine models using 2 systemic allergen sensitisations followed by 3 aeroallergen challenges are prevalent in the literature ([20,29-31]) and have been reported to demonstrate airway hyperresponsiveness to MCh. However, these studies have used enhanced pause (Penh), which is derived from unrestrained barometric plethysmography, to measure changes in lung physiology. As Penh cannot differentiate between constriction in the airways and changes in the tissue compartment of the lungs, it is impossible to tell where the responses to MCh are localised, if indeed they are true physiological responses ([10-14]). In contrast, our study, using 2 systemic sensitisations and 1,3 or 6 challenges, has demonstrated clear airway, tissue or mixed compartment responses to methacholine which is dependent on the number of aerosol challenges delivered. In our hands, the more common model of 2 systemic sensitisations followed by 3 OVA challenges resulted in increased responsiveness to the maximum dose of MCh that was confined to the tissue compartment of the lung. This finding is consistent with a previous study by Tomioka et al. ([17]), which also used a 
forced oscillation technique to measure changes in lung mechanics in OVA sensitised and challenged mice. The fact that the response was confined to the tissues is of interest as the aim of these models is to mimic the human asthmatic condition, in which a significant portion of reactivity of the lungs is localised in the conducting airways ([19]). This work emphasises the importance of measuring bronchoconstriction with physiological techniques capable of compartmentalising responses within the lungs. By varying the antigen dose at challenge we have revealed a system with the potential to allow investigation of transient or prolonged responsiveness to $\mathrm{MCh}$ that is localised in the airways, tissues, or both. Further investigation is needed in order to understand the mechanisms that are influencing the site of responsiveness.

Typically, most human studies measure $\mathrm{MCh}$ responsiveness in terms of sensitivity as they report the concentration of MCh required to produce a $20 \%$ fall in $\mathrm{FEV}_{1}$. We have shown that it is possible to determine sensitivity to inhaled $\mathrm{MCh}$ in mice and that only the airway compartment shows heightened sensitivity following allergic sensitisation and challenge. While increased maximal responses can be seen in both airway and parenchymal compartments, depending on which model is used, no increase in parenchymal sensitivity is seen with any of the models we used. As such, these findings reinforce the value of using lung function techniques that are capable of assessing airway and parenchymal mechanics separately.

Total serum IgE was significantly elevated following systemic sensitisation but was not increased by aerosol challenge. There was, however, a tendency for total serum IgE to decline by day 27 in mice that were systemically sensitised but not challenged with OVA aerosols, compared to mice additionally exposed to 6 OVA aerosols. It is possible that if the study had been extended to include further exposure to antigen over subsequent days, a difference would have been detected between mice that were only sensitised and mice that were sensitised and challenged. Given that antigen specific IgE and other immunoglobulin subtypes were not measured in this study, further work is required to characterise the effect of dose of antigen at challenge on the development of antibody responses to OVA in mice.

The protocol used in the present study induced significant eosinophilia after a single airway challenge. The degree of eosinophilia increased with increasing number of airway challenges. This finding is consistent with several previous studies using similar protocols to induce allergic inflammation in the lungs of mice $([20,29-31])$. While the level of activation of the eosinophils was not measured in the present study, the $61 \%$ eosinophilia found after 6 OVA aerosols was much higher than those that are typically found in human asthmatics ([32]). Given the significant and prolonged parenchymal response to inhaled methacholine following 6 OVA aerosols and the level of eosinophilia present, it is likely that this model more closely parallels an allergic alveolitis ([33]) than the airway inflammation commonly seen in humans.

In recent studies there has been some focus on the association, or lack thereof, between indicators of systemic sensitisation, such as the levels of serum antibodies, airway inflammation and AHR ([34]). In a review of the role of IgE in the induction of eosinophilic airway inflammation and AHR, Hamelmann et al. ([35]) concluded that systemic methods of sensitisation resulted in high levels of IgE and eosinophilic airway inflammation in BALB/C mice. In these models, AHR was determined to be dependent on eosinophils but not IgE. However, the results of our study, which uses a similar protocol to those reviewed by Hamelmann et al. ([35]), show that the presence of eosinophils did not always coincide with an increase in responsiveness to MCh. Three OVA aerosols resulted in a significant eosinophilia after 24 hours but an increase in the response to the maximum dose of $\mathrm{MCh}$ was not evident until 48 hours post challenge. In contrast, a single OVA challenge resulted in hyperresponsiveness to MCh that had resolved by 48 hours while the levels of eosinophils remained significantly elevated. The levels of total serum IgE were equivalent across all challenge doses suggesting that, while the presence of IgE may be necessary to initiate the allergic response, its presence at a particular measurement time point does not necessarily relate to the presence of hyperresponsivenss.

\section{Conclusions}

The findings of the present study demonstrate the significant impact of changing antigen challenge dose in a murine model of allergic bronchopulmonary inflammation. Given the variability of the inflammatory profile and characteristic responses observed in this study, it is clear that investigators must carefully characterise their allergen-driven murine models to ensure the model used contains the characteristic of interest. Future studies need to be directed at understanding the mechanisms that underlie airway and parenchymal hyperresponsiveness post antigen challenge.

\section{Authors' contributions}

GRZ carried out the animal studies and drafted the manuscript. CvG carried out the IgE analysis and assisted in the interpretation of results and editing the manuscript. PAS assisted in the interpretation of results and editing the manuscript. PGH assisted in the conceptualisation of the study and interpretation of the results. PDS and DJT 
assisted in the conceptualisation of the study, interpretation of the results and editing the manuscript.

\section{Acknowledgements}

This project was supported by a National Health and Medical Research Council Program Grant \#2 I 1912. We also thank Sam Gard for preparation of the BAL samples and total cell counts.

\section{References}

I. Bousquet Jean, Jeffrey Peter K., Busse William W., Johnson Malcolm, Vignola Anotonio M.: Asthma: from bronchoconstriction to airways inflammation and remodeling. American Journal of Respiratory and Critical Care Medicine 2000, I61:1720-1745.

2. Trautmann Axel, Schmid-Grendelmeier Peter, Kruger Katja, Crameri Reto, Akdis Mubeccel, Akkaya Ahmet, Brocker Eva-B., Blaser Kurt, Akdis Cezmi A.: T cells and eosinophils cooperate in the induction of bronchial epithelial cell apoptosis in asthma. Journal of Allergy and Clinical Immunology 2002, 109:329-337.

3. Fabbri Leonardo M., Romagnoli Micaela, Corbetta Lorenzo, Casoni Gianluca, Busljetic Kamelija, Turato Graziella, Ligabue Guido, Ciaccia Adalberto, Saetta Marina, Papi Alberto: Differences in airway inflammation in patients with fixed airflow obstruction due to asthma or chronic obstructive pulmonary disease. American Journal of Respiratory and Critical Care Medicine 2003, 167:4 I 8-424.

4. Karjalainen J, Hulkkonen J, Nieminen MM, Huhtala H, Aromaa A, Klaukka T, Hurme M: Interleukin- 10 gene promoter region polymorphism is associated with eosinophil count and circulating immunoglobulin $E$ in adult asthma. Clinical and Experimental Allergy 2003, 33:78-83.

5. Sutherland $E$. Rand, Martin Richard J.: Airway inflammation in chronic obstructive pulmonary disease: comparisons with asthma. Journal of Allergy and Clinical Immunology 2003, I I 2:8 19-827.

6. Drazen JM, Finn PW, De Sanctis GT: Mouse models of airway responsiveness: physiological basis of observed outcomes and analysis of selected examples using three outcome indicators. Annual Review of Physiology 1999, 6 1:593-625.

7. Kumar Rakesh K., Foster Paul S.: Modeling allergic asthma in mice: pitfalls and opportunities. American Journal of Respiratory Cell and Molecular Biology 2002, 27:267-272.

8. Kips JC, Anderson GP, Fredberg J], Herz U, Inman MD, Jordana M, Kemeny DM, Lotvall J, Pauwels RA, Plopper CG, Schmidt D, Sterk PJ, Van Oosterhout AJM, Vargaftig BB, Chung KF: Murine models of asthma. European Respiratory Journal 2003, 22:374-382.

9. Raeburn David, Underwood Stephen L., Villamil Maria Elena: Techniques for drug delivery to the airways, and the assessment of lung function in animal models. Journal of Pharmacology and Toxicological Methods 1992, 27:143-159.

10. Mitzner Wayne, Tankersley Clarke: Noninvasive measurement of airway responsiveness in allergic mice using barometric plethysmography. American Journal of Respiratory and Critical Care Medicine 1998, I58:340-342.

II. Hantos Zoltan, Brusasco Vitoq: Assessment of respiratory mechanics in small animals: the simpler the better? Journal of Applied Physiology 2002, 93: I I 96-I I 97.

12. Lunblad Lennart K. A., Irvin Charles G., Andler Andy, Bates Jason H. $T$.: A reevaluation of the validity of unrestrained plethysmography in mice. Journal of Applied Physiology 2002, 93: I 198- 207.

13. Adler A, Cieslewicz G, Irvin CG: Unrestrained plethysmography is an unreliable measure of airways responsiveness in BALB/ c and C57BL6 mice. J Appl Physiol 2004, 97:286-292.

14. Bates Jason H. T., Irvin CG, Brusasco Vito, Drazen JM, Fredberg JJ, Loring Stephen, Eidelman David, MacKlem Peter, Martin James, MilicEmili J, Hantos Z, Hyatt Robert, Lai-Fook Stephen, Leff Alan, Solway Julian, Lutchen Kenneth R., Suki B, Mitzner Wayne, Pare Peter, Pride Neil, Sly Peter D.: The use and misuse of Penh in animal models of lung disease. American Journal of Respiratory Cell and Molecular Biology 2004, 31 I:373-374.

15. Petak Ferenc, Habre Walid, Donati Yves R., Hantos Zoltan, Barazzone-Argiroffo Constance: Hyperoxia-induced changes in mouse lung mechanics: forced oscillations vs. barometric plethysmography. Journal of Applied Physiology 200I, 90:222 I-2230.

16. Hantos Z, Daroczy B, Suki B, Nagy S, Fredberg JJ: Input impedance and peripheral inhomogeneity of dog lungs. Journal of Applied Physiology 1992, 72:168-178.
17. Tomioka Shinichiro, Bates Jason H. T., Irvin CG: Airway and tissue mechanics in a murine model of asthma: alveolar vs forced oscillations. Journal of Applied Physiology 2002, 93:263-270.

18. Collins Rachel A., Sly Peter D., Turner Debra J., Herbert Cristan, Kumar Rakesh K.: Site of inflammation influences site of hyperresponsiveness in experimental asthma. Respiratory Physiology and Neurobiology 2003, I39:5I-6I.

19. Kaczka David W., Ingenito Edward P., Israel Elliot, Lutchen Kenneth R.: Airway and lung tissue mechanics in asthma: effects of albuterol. American Journal of Respiratory and Critical Care Medicine 1999, 159:169-178.

20. Gerhold Kirsten, Blumchen Katherina, Bock Anja, Seib Christine, Stock Phillipe, Kallinich Tilmann, Lohning Max, Wahn Ulrich, Hamelmann Eckard: Endotoxins prevent murine IgE production, Th2 immune responses, and development of airway eosinophilia but not airway hyperreactivity. Journal of Allergy and Clinical Immunology 2002, I 10:1 10-116.

21. Humbles Alison A., Bao Lu, Friend Daniel S., Okinaga Shoji, Lora Jose, Al-garawi Amal, Martin Thomas R., Gerard Norma P., Gerard Craig: The murine CCR3 receptor regulates both the role of eosinophils and mast cells in allergen-induced airway inflammation and hyperresponsiveness. Proceedings of the National Academy of Sciences of the United States of America 2002, 99: | 479-1484.

22. Reader J. Rachel, Tepper Jeffrey S., Schelegle Edward S., Aldrich Melinda C., Putney Lei F., Pfeiffer Juergen W., Hyde Dallas M.: Pathogenesis of mucous cell metaplasia in a murine asthma model. American Journal of Pathology 2003, 162:2069-2078.

23. Knott Patrick G., Gater Paul R., Bertrand Claude P.: Airway inflammation driven by antigen-specific resident lung CD4+ T-cells in aB-T cell receptor transgenic mice. American Journal of Respiratory and Critical Care Medicine 2000, I6 I:1340-1348.

24. Williams Cara .M.M, Galli Stephen J.: Mast cells can amplify airway rectivity and features of chronic inflammation in an asthma model in mice. Journal of Experimental Medicine 2000, 192:455-462.

25. De Sanctis GT, MacLean James A., Qin Shixin, Woylniec Walter W., Graseman Hartmut, Yandava Chandri, N., Jioa Aiping, Noonan Thomas, Stein-Streilein Joan, Green Francis H. Y., Drazen JM: Interleukin-8 receptor modulates IgE production and B-cell expansion and trafficking in allergen-induced pulmonary inflammation. Journal of Clinical Investigation 1999, 103:507-515.

26. Tomkinson A, Cieslewicz Greg, Duez Catherine, Larson Kirsten A., Lee James J., Gelfand Erwin W.: Temporal association between airway hyperresponsivenss and airway eosinophilia in ovalbumin-sensitized mice. American Journal of Respiratory and Critical Care Medicine 200I, 163:72I-730.

27. Pillow JJ, Korfhagen TR, Ikegami M, Sly Peter D.: Overexpression of TGF-alpha increases lung tissue hysteresivity in transgenic mice. Journal of Applied Physiology 2001, 91:2730-2734.

28. Fredberg Jeffrey J., Stamenovic Dimitrije: On the imperfect elasticity of lung tissue. Journal of Applied Physiology 1989, 67:2408-24I9.

29. Hopfenspirger MT, Agrawal DK: Airway hyperresponsiveness, late allergic response, and eosinophilia are reversed with mycobacterial antigens in ovalbumin-presensitized mice. Journal of Immunology 2002, 168:251 6-2522.

30. Kwak Yeon-Geun, Song Chang H., Yi Ho K., Hwang Pyoung H., Kim Jong-Suk, Lee Kyung S., Lee Yong C.: Involvement of PTEN in airway hyperresponsiveness and inflammation in bronchial asthma. Journal of Clinical Investigation 2003, I I I:1083-1092.

31. Rha YH, Taube C, Haczku A, Joetham A, Takeda K, Duez C, Siegel M, Aydintug MK, Born WK, Dakhama A, Gelfand EW: Effect of microbial heat shock proteins on airway inflammation and hyperresponsiveness. Journal of Immunology 2002, 169:5300-5307.

32. Niimi A, Amitani R, Suzuki E. Tanaka, Murayama T, Kuze F: Eosinophilic inflammation in cough variant ashtma. European Respiratory Journal 1998, I I: 1064-1069.

33. Temelkovski Jason, Hogan Simon P., Shepherd Darren P., Foster Paul S., Kumar Rakesh K.: An improved murine model of asthma: Selective airway inflammation, epithelial lesions and increased methacholine responsiveness following chronic exposure to aerosolised allergen. Thorax 1998, 53:849-856.

34. Wilder Julie A, Collie David S, Wilson Bridget S, Bice David E, Lyons Richard, Lipscomb Mary F: Dissociation of airway hyperresponsiveness from immunoglobulin $E$ and airway eosinophilia in a murine model of allergic asthma. American Journal of Respiratory Cell and Molecular Biology 1999, 20: I326-I334. 
35. Hamelmann E, Tadeda K, Oshiba A, Gelfand Erwin W.: Role of IgE in the development of allergic airway inflammation and airway hyperresponsiveness. Allergy 1999, 54:297-305.

Publish with Bio Med Central and every scientist can read your work free of charge

"BioMed Central will be the most significant development for disseminating the results of biomedical research in our lifetime. " Sir Paul Nurse, Cancer Research UK

Your research papers will be:

- available free of charge to the entire biomedical community

- peer reviewed and published immediately upon acceptance

- cited in PubMed and archived on PubMed Central

- yours - you keep the copyright

Submit your manuscript here:

http://www.biomedcentral.com/info/publishing_adv.asp
BioMedcentral 